\title{
CONTRIBUIÇÃO AO ESTUDO DA RESSEDIMENTAÇÃO NO SUBGRUPO ITARARÉ: TRATOS DE FÁCIES E HIDRODINÂMICA DEPOSICIONAL
}

\author{
ERCÍLIO G. GAMA, Jr.*, JOSÉ AJ. PERINOTTO*, HÉLIO J.P.S. RIBEIRO** e EDUARDO K. PADULA***
}

\begin{abstract}
CONTRIBUTION TO THE STUDY OF RESEDIMENTATION IN THE HARARE SUBGROUP: FACIES TRACTS AND HYDRODYNAMICS. This paper is a contribution to the resedimentation facies analysis in the Permo-Carboniferous Itararé Subgroup, Paraná Basin, southeast Brazil, and it is complemented by a thematic field guide for Porto Feliz region, São Paulo State. Two facies tracts were identified. The confined tract (identified by erosional features at the base of the deposits) is composed by a transitional facies set typified by the following end-members: disorganized diamictites, organized diamictites or conglomerates, stratified sandstones, and massive sandstones. To the unconfined tract belong the following transitional spectrum end-members: disorganized diamictites, graded rhythmites, varvic rhythmites and their disturbed equivalents. The origin of resedimentation hydrodynamic process is essentially gravitational. It starts when the glaciogenic deposits are remolded upon flooding by marine transgressions. The unstable remolded deposits are submited to debris flows which evolve to high concentration turbidity currents under confined conditions. At the end of this continuous process the turbidity current interplays with traction, grain interaction and fluidization. The debris flows under unconfined conditions evolve directly to low concentration turbidity currents and from these to diluted suspensions. As the deposition may take place at any moment in those continuous flow spectra, the resultant deposits show continuous transition in their facies characteristics. The presence and abundance of resedimentation facies in the Itararé Subgroup attest that the glaciers were more important functioning as a supply agents than depositional agents.
\end{abstract}

Keywords: Itararé Subgroup, resedimentation, ParanaBasin, facies tract, Permian, Permo-Carboniferous, depositional hydrodynamic, sedimentary geology.

\begin{abstract}
RESUMO Esta contribuição trata de uma análise de fácies de ressedimentação do Subgrupo Itararé, Permocarbonífero da Bacia do Paraná, e é complementada por um guia de campo temático na região de Porto Feliz, no Estado de São Paulo. São reconhecidos dois tratos de fácies. O trato confinado, identificado pela presença de feições erosivas na base dos depósitos, é constituído por uma família de fácies transicionais tipificadas pelos seguintes elementos discretos: diamictitos desorganizados, diamictitos ou conglomerados organizados, arenitos estratificados e arenitos macicos. $\mathrm{O}$ trato não-confinado inclui os seguintes elementos discretos de um espectro transicional: diamictitos desorganizados, ritmitos gradados, ritmitos várvicos e seus equivalentes deformados. A hidrodinâmica envolvida na ressedimentação é de natureza essencialmente gravitational e inicia-se com a amolgação de depósitos glaciogênicos, quando submersos por transgressões marinhas. Em equilíbrio instável, os depósitos amolgados são submetidos a fluxos de detritos que, em condições confinadas, evoluem para correntes de turbidez de alta concentração e, nos momentos finais, para processos tracionais, interação de grãos e fluidização. Em condições não-confinadas, os fluxos de detritos evoluem diretamente para correntes de turbidez de baixa concentração e destas, para suspensões diluídas. Como a deposição pode ocorrer em qualquer momento destes dois contínuos espectros de fluxos, os depósitos resultantes exibem contínua transição em suas características faciológicas, configuradas nos tratos reconhecidos. A presença e abundância de fácies de ressedimentação no Subgrupo Itararé atestam que os glaciares desempenharam uma função mais relevante como agentes de suprimento do que como agentes deposicionais.
\end{abstract}

Palavras-chaves: Subgrupo Itararé, ressedimentação, Bacia do Paraná, trato de fácies, Permiano, Permocarbonífero, hidrodinâmica deposicional, geologia sedimentar.

INTRODUÇÃO A origem glacial dos sedimentos Itararé acha-se estabelecida desde Derby (1878) que correlacionou tais depósitos a camadas glaciais permianas da Índia e Austrália.Seguiram-se importantes contribuições como as de Woodworth (1912), Coleman (1918), Washburne (1930), que ofereceram importantes observações sobre a idade e relações espaciais dos sedimentos glaciogênicos, reportando a presença de seixos facetados e estriados e associações com sedimentos marinhos. Importantes considerações paleogeográficas sobre as ligações desses depósitos com os da África do Sul e Austrália foram igualmente ressaltadas.

Nos anos que se seguiram, destacou-se o trabalho de Leinz (1937) apresentando um modelo glacial continental, no qual achavam-se presentes idéias como caracterização de verdadeiros tilitos, direção do movimento das geleiras e ciclos glaciais. Este trabalho serviu de referencial para os estudos subseqüentes, cujos autores, embora reconhecendo fácies marinhas associadas, preconizavam um modelo fundamentalmente continental e lacustre.
A subdivisão e classificação estratigráfica dos mais de mil metros de sedimentos do Subgrupo Itararé monopolizaram as pesquisas principalmente até a década de sessenta. Barbosa \& Almeida (1949), Petri (1964), Rocha-Campos (1967), Northfleet et al (1969) apresentaram diversas propostas neste sentido.

A partir dos anos setenta, os autores retomam suas atenções para a problemática genética, diferenciando fácies glaciogênicas e reconhecendo associações genéticas de fácies (Frakes \& Crowell 1969, Landim \& Barros 1972 e Fulfaro \& Landim 1976). Ne sta linha de pesquisa, os estudos faciológicos ofereceram interpretações bastante diversificadas e frequientemente contraditórias. Soares et al (1977) e Landim \& Soares (1979) interpretaram condições lacustres e flúvio-glaciais na porção sul do Estado de São Paulo e condicões marinhas e deltaicas nas regiões leste e centro do Estado. Saad (1977) e Santos (1979) endossaram as condições marinhas para o centro do Estado e reconheceram evidências de incursões marinhas esporádicas na atual faixa de afloramentos. Sistemas costeiros, particularmente deltaicos, foram identificados em várias áreas

\footnotetext{
* Departamento de Geologia Sedimentar, Instituto de Geociências e Ciências Exatas, UNESP, Campus de Rio Claro, Caixa Postal 178, CEP 13500-970, Rio Claro, SP, Brasil

** Departamento de Geologia/Centro Tecnológico, Universidade do Vale do Rio dos Sinos, Caixa Postal 275, CEP 93020-000, São Leopoldo, RS, Brasil

*** Ex-bolsista de Iniciação Científica da Fapesp, Processo 88/1968-5
} 
do Estado. Gama et al (1980), Fulfaro et al. (1984), Stevaux et al (1986) e Perinotto (1987) identificaram fácies ou lobos deltaicos na região do médio Rio Tietê. Na região de Itaporanga, Caetano-Chang \& Landim (1983) reconheceram vários lobos deltaicos posteriormente designados por Sistema Deltaico Itaporanga. Leques aluviais, planícies de outwash, sistemas de plataforma e leques subaquosos são igualmente reconhecidos nos trabalhos mais recentes (Caetano-Chang 1984, Souza 1986 e Santos 1987). Paralelamente, feições sedimentares consideradas como registro de ação direta do gelo continuavam sendo postuladas. Rocha-Campos \& Sundaram (1981) e Gravenor \& Rocha-Campos (1983) descreveram lagos proglaciais, tilitos de alojamento e vales glaciais.

Da análise destes trabalhos, executados durante mais de cem anos de pesquisas, depreende-se que, a exemplo dos modelos holocênicos, a sedimentação glacial Itararé é extremamente diversificada faciologicamente e constituída por um trato de sistemas deposicionais bastante complexo. Observa-se ainda que a ação direta dos glaciares como agentes deposicionais dos diamictitos, ou sua proximidade no desenvolvimento de outras fácies arenosas e rítmicas, nunca foi totalmente questionada. Não obstante, os estudos mais recentes em sedimentação glacial, tanto em modelos holocênicos quanto no registro geológico, demonstram que a aplicação das técnicas de análise de fácies tem revelado a abundância de fácies de ressedimentação, associadas e intercaladas a fácies marinhas ou mesmo costeiras (Eyles et al. 1983 e Miall 1983). Estas fácies, que abrangem não só os diamictitos como também os arenitos e ritmitos, são depósitos gerados por fluxos gravitacionais subaquosos a partir do retrabalhamento dos verdadeiros tilitos. Estes são considerados depósitos de muito baixo potencial de preservação (Miall 1985), como decorrência da deterioração provocada pelo degelo. Com esta abordagem, os glaciares são enfocados, prioritariamente, como fontes de sedimentos e, subordinadamente, como agentes deposicionais. Os fluxos gravitacionais seriam os verdadeiros e efetivos agentes deposicionais, enquanto os glaciares desempenhariam principalmente a função de agentes de suprimento de terrígenos.

É nesta linha de pesquisa que se situa este trabalho, cujo objetivo maior é reconhecer e demonstrar a presença de algumas fácies de ressedimentação no Subgrupo Itararé em São Paulo. As conclusões oferecidas devem ser entendidas como interpretações, perfeitamente compatíveis com diversas reconstruções paleogeográficas postuladas para esta unidade estratigráfica. Os trabalhos concentraram-se numa área limitada (região de Porto Feliz) a fim de permitir a elaboração de um guia de campo que servisse de roteiro para excursões didáticas em forma de debates. O propósito último almejado esgota-se na análise de fácies, não pretendendo oferecer reinterpretações paleogeográficas ou questionar interpretações mais abrangentes, formuladas em escala de bacia. O referido guia de campo é apresentado em artigo associado, complementando a temática estudada.

METODOLOGIA A principal motivação para este trabalho foi a melhor compreensão dos fluxos gravitacionais e seus depósitos (Middleton \& Hampton 1976, Lowe 1979, 1982 e Pickering et al 1986) e a afinidade genética destes processos com a sedimentação glacial (Eyles et al. 1983 e Miall 1983). A metodologia utilizada apoia-se na aplicação das técnicas de Análise e Modelos de Fácies (Walker 1984) que prescreve uma minuciosa descrição das fácies, camada por camada. Estas fácies são diferenciadas com ênfase na granulometria, variações verticais na textura e acamamento, estruturas sedimentares e relações de contato.

As fácies foram descritas usando o esquema classificatório proposto por Eyles et al (1983). Cada fácies é identificada por um sistema codificado que consiste numa série de letras correspondentes, mnemonicamente, às mais importantes características sedimentológicas. As três principais classes de fácies - diamictitos, arenitos e finos - são designadas, respectivamente, pelas letras maiúsculas $\mathrm{D}, \mathrm{S}$ e $\mathrm{F}$. Embora algumas análises granulométricas tenham sido realizadas, tal procedimento é considerado dispensável (Miall 1983). Em cada classe, as diferentes fácies são identificadas pela aposição de letras minúsculas indicativas dos principais atributos, conforme a tabela 1 .

Tabela 1 - Codificação descritiva das fácies glaciogênicas Table 1 - Descriptive code of the glaciogenic facies

D = Diamicrito

Dm = suportado pela matriz

De = suportado por clastos

D-m $=$ macico

D-s = estratificado (stratified)

$S=$ Arenito (sandstone)

$\mathrm{Sr}=$ com marcas onduladas (ripples)

Sh $=$ com laminaçăo horizontal

$\mathrm{Sm}=$ maciço

St $=$ com cruzadas acanaladas (trough)

$S-g=$ com gradaçăo

$S-d=$ com seixos pingados (dropstones)

$F \quad=$ Finos

$\mathrm{Fm}=$ maciço

Fi = laminado

$\mathrm{Flp}=$ laminado com pseudonódulos

$\mathrm{F}-\mathrm{d}=$ com seixos pingados (dropstones)

O termo tilito é aqui evitado, pois se reveste de uma conotação genética, qual seja, um depósito formado diretamente pela ação da geleira sem nenhum retrabalhamento subseqüente (Boulton 1981). Da mesma forma, evita-se o termo genético varvito.

Os trabalhos de campo envolveram a investigação dos afloramentos expostos nas rodovias existentes nas adjacências da cidade de Porto Feliz, delimitados por um círculo de $40 \mathrm{~km}$ de raio. Embora a maioria destes afloramentos pertença ao terço inferior aflorante do Subgrupo Itararé, não houve uma preocupação de subordinar esta análise a um determinado intervalo estratigráfico em razão de dois fatores. O primeiro decorre do objetivo pretendido, qual seja, uma interpretação sedimentológica e não paleogeográfica. O segundo, devido à abundante recorrência de fácies, como conseqüência da natureza cíclica da sedimentação glacial Itararé (Leinz 1937, Rocha-Campos 1967).

\section{DESCRIÇÃO DAS FÁCIES DE RESSEDIMENTAÇÃO}

Neste trabalho, entende-se como fácies de ressedimentação qualquer depósito formando por fluxos gravitacionais (Miall 1983). Estes abrangem desde simples deslizamentos de material coeso até fluxos turbulentos de baixa concentração, incluindo fluxos de massa de viscosidade variável (Middleton \& Hampton 1976). Os depósitos gerados reúnem diamictitos, arenitos e ritmitos.

Diamictitos Os diamictitos aflorantes na área estudada são compostos por uma mistura heterogênea de clastos decimétricos e centimétricos imersos em matriz arenosa e/ou lamítica. Os clastos são arredondados e, por vezes, facetados e de composição polimítica. De um modo predominante, os diamictitos são maciços (fácies Dmm), mas podem, por vezes, apresentar uma incipiente organização (fácies Dcm) pelo desenvolvimento de gradação inversa ou normal, imbricação de seixos no plano horizontal e mesmo estratificação plano-pa- 
ralela (Dms). Esta organização parece ser mais efetiva em diamictitos de matriz arenosa, nos quais foi possível reconhecer uma gradativa transição entre as fácies Dcm, Dms e DCS. Os contatos basais podem ser erosivos, com os diamictitos preenchendo canais anteriormente escavados (Foto 1), ou concordantes, com o desenvolvimento de estruturas de sobrecarga.

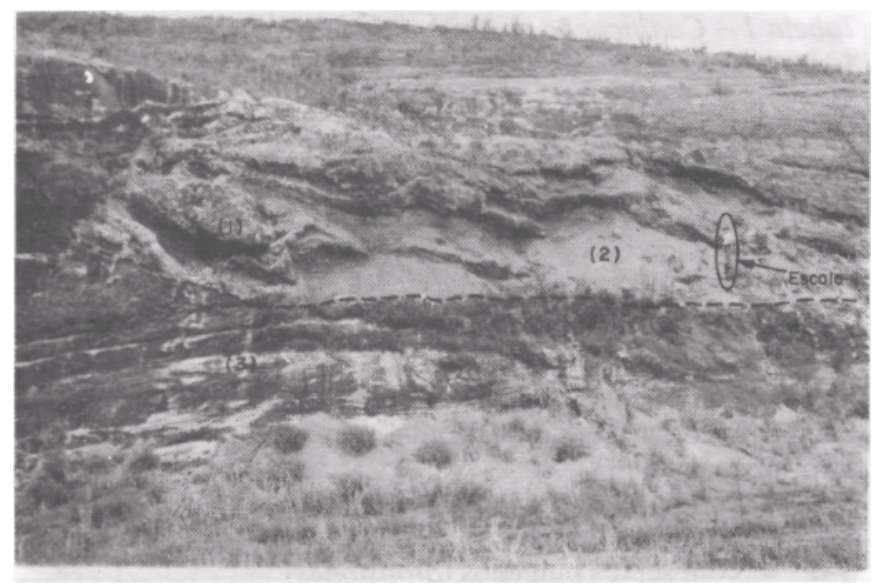

Foto 1 -Afloramento 1. Rodovia do Açúcar (SP-308), $\mathrm{km}$ 101. Corpos lenticulares de diamictitos desorganizados (1) deformados por lutocinese (2), preenchendo canal escavado em arenitos estratificados (3). Localização: $n^{o} 1$ na figura 1 do trabalho seguinte (Gama et al. 7992)

Photo 1 - Outcrop 1. Açúcar Highway (SP-308), km. 101. Lenticular disorganized diamictite bodies (1) deformed by mud diapirism (2), filling up a channel scoured in stratified sandstone (3). Localization: n. 1, figure 1 in the next paper (Gama et al. 1992)

Outra característica marcante nestes depósitos é a abundância de deformação plástica, com o desenvolvimento de dobramentos convolutos e descontínuos. Este aspecto só é observável em diamictitos organizados pela presença de estratificação como referencial.

Arenitos Os arenitos variam desde conglomeráticos, em bancos métricos, até muito finos, em camadas centimétricas ou mesmo lentes. Os depósitos mais espessos exibem estratificação bem desenvolvida com predominância de cruzadas acanaladas; cruzadas planares não são, entretanto, raras. A gradação normal é freqüente (fácies $\mathrm{Sg}$ ) tanto nos arenitos grossos quanto nos finos. Gradação inversa não foi constatada, embora na literatura seja mencionada para os arenitos conglomeráticos. Os contatos entre as camadas são abruptos, freqüentemente escavados nos sedimentos sotopostos. A partir de uma granulometria fina é comum o desenvolvimento de laminações cruzadas cavalgantes (climbing ripples cross laminations) (Foto 2), que se tornam freqüentes em arenitos muito finos. Esses abrangem as fácies $\mathrm{Sr}$ e $\mathrm{Sn}$. Na fácies $\mathrm{Sr}$, as laminações cruzadas cavalgantes manifestam-se em camadas onduladas (wavy) e lenticulares (linsen), intercaladas em sedimentos pelíticos que apresentam ainda uma sutil gradação normal. Por outro lado, na fácies Sh, estas feições estão ausentes, predominando a laminação horizontal abrupta. Seixos pingados são freqüentes, mas só observáveis quando estes arenitos encontram-se associados a pelitos.

Finalmente, os arenitos maciços (fácies $\mathrm{Sm}$ ) são bem selecionados na fração fina a média e caracterizados, obviamente, pela ausência de qualquer organização. Mesmo os acamamentos estão ausentes ou mal desenvolvidos. As únicas estruturas observáveis são as de escape d'água.

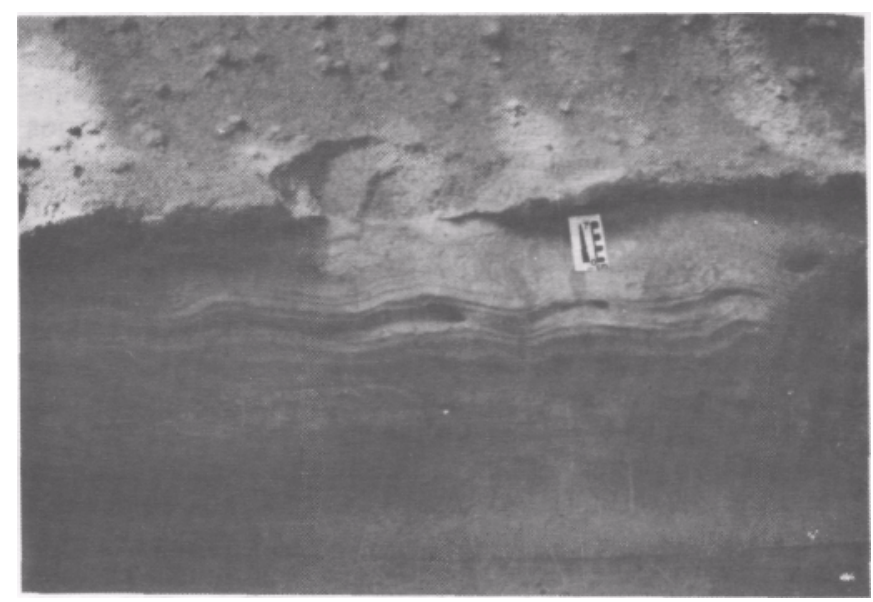

Foto 2 - Afloramento da Gruta de Porto Feliz (n ${ }^{\circ}$ 2). Bancos de arenito com gradação normal (Sg). Observar o contato entre arenito maciço (banco superior) sobre arenito fino com laminações cruzadas cavalgantes sinusoidais (banco inferior). Localização: $n$-2 na figura l do trabalho seguinte (Gama et al. 7992)

Photo 2 - Outcrop 2. Porto Feliz Grotto. Sandstone banks with normal grading $(\mathrm{Sg})$. Note the contact between massive sandstone (upper bank) on a fine sandstone with sinusoidal climbing ripple cross-lamination (lower bank). Localization: $\mathrm{n}$. 2, figure 1 in the next paper (Gama et al. 1992)

Ritmitos Ao lado dos diamictitos, os ritmitos são os sedimentos mais conspícuos do Subgrupo Itararé na região de Porto Feliz. A pedreira de Itu é uma belíssima exposição destes ritmitos e referencial de estudos geológicos desde há várias décadas. No presente trabalho foram reconhecidos dois tipos predominantes de ritmitos. Num, o caráter rítmico é emprestado pela própria fácies $\mathrm{Fl}$, cuja laminação horizontal separa estratos milimétricos a centimétricos de silte e argila com contato abrupto, conferindo-lhe o aspecto várvico. O outro é caracterizado pela intercalação das fácies $\mathrm{Sr} / \mathrm{Sg}$ e a própria $\mathrm{Fl}$, cuja distinção é nítida pela presença de gradação, laminações cruzadas cavalgantes e acamamento wavy ou linsen na fácies $\mathrm{Sr}$ (Foto 3). Um terceiro tipo, menos freqüente, são depósitos com ritmicidade emprestada pela intercalação da fácies $\mathrm{Sm}$, em camadas decimétricas, com a fácies $\mathrm{Fl}$, em estratos milimétricos. Deformações plásticas em dobramentos caóticos e estratais e seixos pingados são outras feições que completam a caracterização dos ritmitos nesta região.

\section{TRATOS DE FÁCIES DE RESSEDIMENTAÇÃO}

caráter transicional entre as fácies estudadas é um traço marcante nos depósitos de ressedimentação. Constituem, de fato, uma família de fácies unidas pela vinculação genética dos processos sedimentares envolvidos. Todos de natureza gravitacional. Neste contexto, foi possível reconhecer dois diferentes tratos de fácies, controlados pelo grau de confmamento dos processos gravitacionais responsáveis. Vale dizer, foram identificados dois diferentes direcionamentos de transição faciológica. $\mathrm{O}$ caráter confinado é evidenciado pela presença de feições erosivas na base dos depósitos e, principalmente, pelo sentido da variação no teor de argila ao longo da transição.

Trato confinado Este trato, marcado por um contínuo decréscimo no teor de argila, foi desenvolvido em condições confinadas em canais ou vales subaquosos. A transição se faz da fácies Dmm para a Sm, englobando as demais fácies diamictíticas e arenosas. Nos diamictitos, a transição é ainda evidenciada pelo crescente grau de organização, iniciando-se com o desenvolvimento de gradação inverso-normal, imbricação de seixos e, finalmente, no aparecimento da estratificação, tornando-se conglomerados arenosos. A partir de então, a 


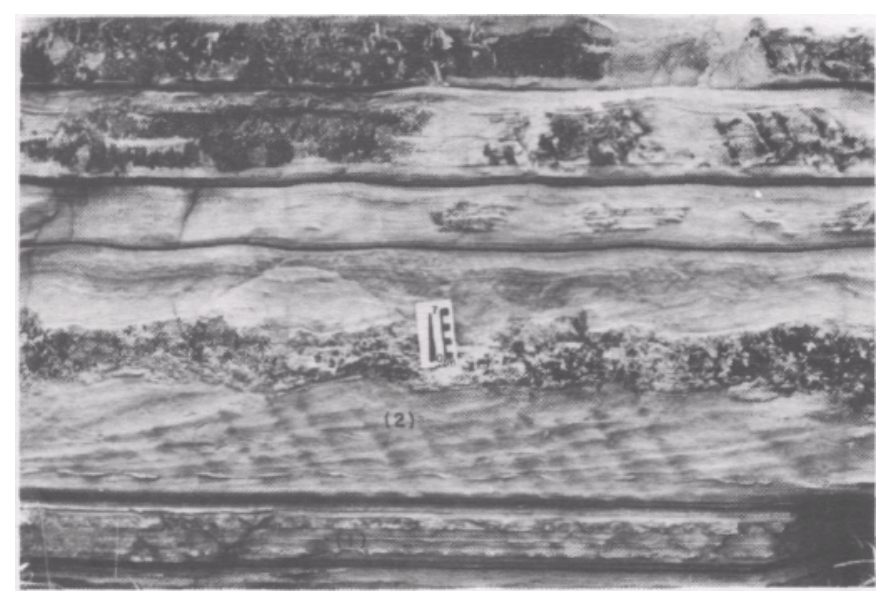

Foto 3 - Pedreira de Itu (afloramento $n^{\circ} 5$ ). Dois tipos de ritmitos. Ritmitos várvicos na base (1) e ritmitos gradados com laminações cruzadas cavalgantes acima (2). Localização: $n^{\circ} 5$ na figura 1 do trabalho seguinte (Gama et al. 1992)

Photo 3 - Outcrop 5. Itu Quarry. Two types of rhythmites. Varved rhythmites bellow (1) and graded rhythmites with climbing ripple cross-lamination above (2). Localization: n. 5, figure 1 in the next paper (Gama et al. 1992)

transição é melhor ressaltada pela diminuição granulométrica, até arenitos de granulação média. A fácies $\mathrm{Sg}$, a mais freqüente na área estudada, apresenta-se neste trato com granulometria média a grossa. A transição é completada com o gradativo desaparecimento das estruturas sedimentares até o arenito tornar-se maciço (fácies $\mathrm{Sm}$ ). A figura 1 descreve esta transição, relacionando as diferentes fácies com a contínua alteração dos atributos faciológicos.

Para efeito de interpretação da dinâmica deposicional, a transição de fácies do trato confinado é modelada por quatro litofácies, a saber: Diamictitos Desorganizados, Diamictitos Organizados, Arenitos Estratificados e Arenitos Maciços. Estas litofácies representam elementos discretos desta transição e se prestam como modelos ideais para análise faciológica. Os processos sedimentares envolvidos são aqui atribuídos a fluxos de detritos coesivos, que, por decréscimo da viscosidade e conseqüente aumento da velocidade, passam para correntes de turbidez de alta concentração e, finalmente, fluidização, em decorrência de rápida desaceleração do fluxo. Como a deposição pode ocorrer em qualquer estágio desta gradativa mudança de propriedades físicas do fluxo gravitacional, as fácies resultantes apresentam-se com características marcadamente transicionais.

Trato não-confinado Ao contrário do anterior, este segundo trato é caracterizado pelo crescente aumento no teor de argila, razão pela qual é inferido seu desenvolvimento em condições não-confmadas. Este trato inicia-se, igualmente, com a fácies Dmm que, pela contínua rarefação de seixos e calhaus, passa para lamitos ou arenitos seixosos e, finalmente, para ritmitos. Inicialmente, os ritmitos são compostos por intercalações das fácies $\mathrm{Fl}$ e $\mathrm{Sr} / \mathrm{Sg}$. A fácies $\mathrm{Sg}$, ao contrário do que lhe ocorre no trato anterior, é representada por arenitos finos, mantendo-se gradados e com laminações cruzadas cavalgantes. Neste estágio, a transição do trato é detectada pela abundância relativa das fácies $\mathrm{Fl}$ e $\mathrm{Sg}$, com a contínua diminuição da fácies $\mathrm{Sg}$, até se limitar à fácies $\mathrm{Fl}$ exclusivamente, à semelhança dos varvitos. Este trato de fácies é ainda caracterizado pela abundância de depósitos deformados e convolutos, tanto de diamictitos quanto de ritmitos. A figura 2 descreve este trato através de seus atributos faciológicos.

A modelagem deste espectro de fácies é representada pelas seguintes litofácies: diamictitos desorganizados, ritmitos gradados, ritmitos várvicos e ritmitos deformados, com uma variante para incluir os Diamictitos Deformados. Os processos sedimentares interpretados neste trabalho incluem fluxos de detritos, correntes de turbidez de baixa concentração, decantação de suspensões diluídas e deslizamentos. A ausência de correntes de turbidez de alta concentração neste trato é atribuída ao não-desenvolvimento de altas velocidades na passagem do fluxo laminar para turbulento.

HIDRODINÂMICA DA RESSEDIMENTAÇÃO Os processos de ressedimentação, responsáveis por determinadas fácies presentes no Subgrupo Itararé, relacionam-se à transgressão que se processou em ciclos espasmódicos e que resultaram nos episódios de sedimentação glaciogênica, reconhecidos por Leinz (1937) como ciclos glaciais. Em cada ciclo, as relações de campo indicam que após uma fase inicial de ativa progradação dos lobos glaciais, continentais ou marinhos, seguiu-se um afogamento das áreas anteriormente ocupadas pelas geleiras, ampliando as dimensões da bacia e colocando fora de equilíbrio seu perfil deposicional. Como decorrência, os depósitos glaciais, particularmente os tilitos continentais, passaram a ocupar uma posição instável para o novo meio, propiciando sua canibalização por processos gravitacionais e conseqüente ressedimentação em condições subaquosas marinhas.

A hidrodinâmica envolvida em cada episódio deposicional inclui: a. mecanismos de iniciação dos processos, b. processos de transporte a longa distância e c. modificações finais sin ou pós-deposicionais.

Para a iniciação dos processos são postulados dois mecanismos: amolgação (remolding) dos depósitos glaciais e turbulência gerada por fluxos hiperpicnais. Os depósitos glaciais ao serem submersos sofrem infiltração de água, tornando-se saturados. $\mathrm{O}$ aumento da pressão intersticial (pore pressure), provocado pela saturação, resulta no desarranjo da estrutura interna destes depósitos, ao mesmo tempo que a maior viscosidade da água infiltrada impede que os grãos se rearrangem novamente. Nesta situação amolgada, os fragmentos elásticos aparentemente flutuam na água intersticial. Amolgação também deve ter ocorrido em tilitos empurrados mar adentro por geleiras costeiras. $\mathrm{O}$ segundo mecanismo apto à iniciação de processos gravitacionais é a turbulência gerada pela descarga de águas de degelo que tenham retrabalhado os depósitos glaciais. Estas águas, ao adentrarem um corpo aquoso, geram, necessariamente um fluxo hiperpicnal em razão da sua maior densidade. Esta maior densidade é conferida não só pela alta concentração de sedimentos em suspensão, mas também por sua baixa temperatura.

$\mathrm{Na}$ iniciação dos processos via amolgação, os depósitos glaciais, compostos por cascalhes, areias e argilas, saturados de água, encontram-se num estado semi-fluido e em repouso instável. Esta massa só irá fluir quando a força devida à gravidade superar a resistência de atrito interno. No Subgrupo Itararé, esta condição pode ter sido favorecida por várias eventualidades, tais como, ablação de geleiras costeiras, desmoronamentos de sedimentos, queda de blocos de icebergs ou mesmo pelo avanço de geleiras mar adentro, a exemplo do postulado por Miall (1983) para a Formação Gowganda do Proterozóico da América do Norte.

Iniciado o movimento, a hidrodinâmica envolvida abrange uma série de fluxos viscosos de natureza gravitacional. Estes fluxos, de viscosidade variável, compõem um contínuo e transicional espectro que realiza o transporte de sedimentos bacia adentro. O caráter transicional é decorrência da variação das propriedades físicas dos fluxos que se alteram continuamente durante o episódio de transporte, seja no domínio do tempo de duração ou da distância percorrida. Estas propriedades físicas incluem densidade e viscosidade da mistura água-sedimento, concentração de sedimentos e declividade da superfície submersa, as quais, por sua vez, refletem-se na fluidez e velocidade 


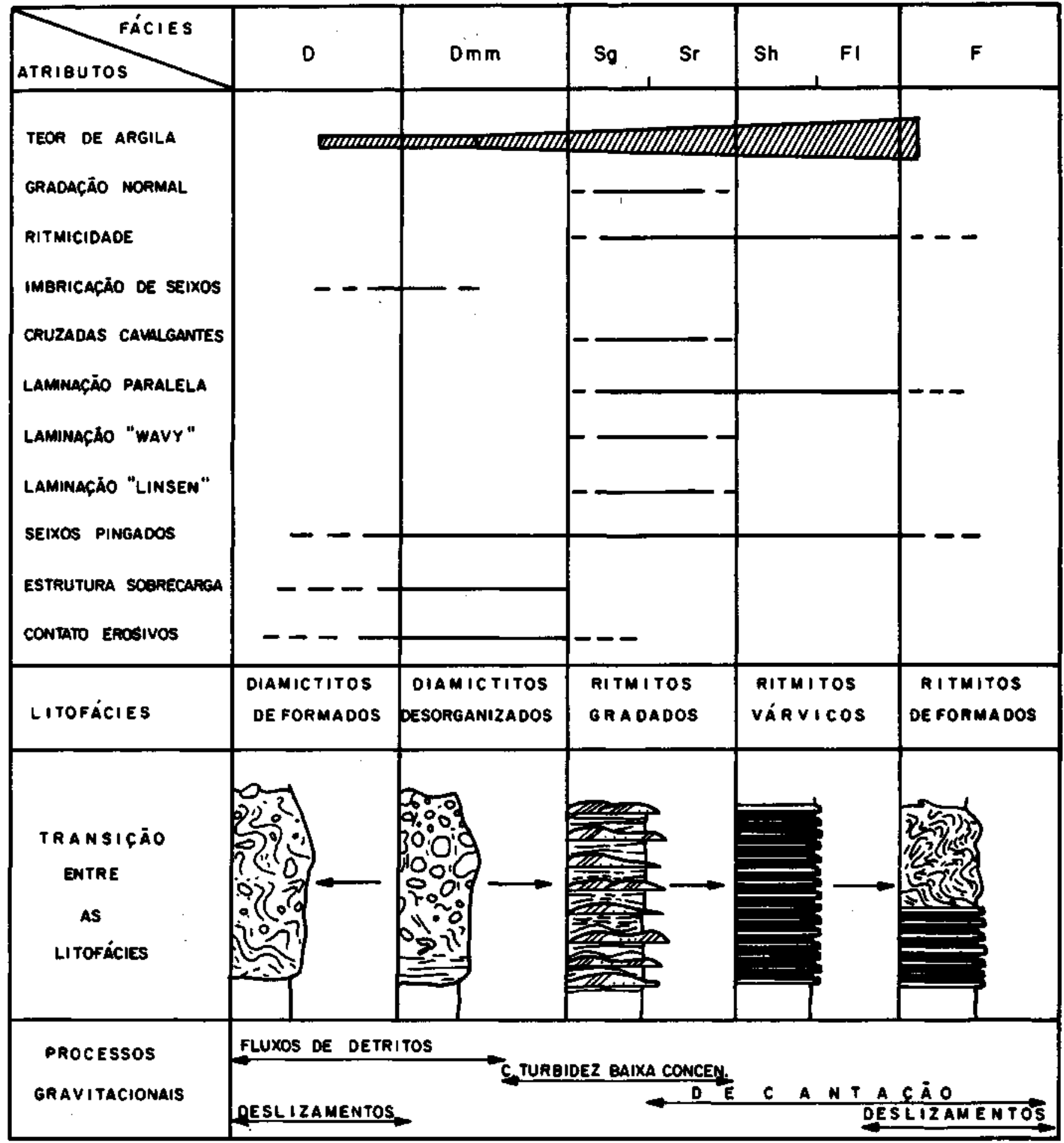

Figura 1 - Trato confinado de fácies de ressedimentação do Subgrupo Itararé na região de Porto Feliz (SP) Figure 1 - Resedimentation confined facies tract of the Itararé Subgroup in the Porto Feliz city region (São Paulo State)

do fluxo e no mecanismo de suporte dos grãos (Middleton \& Hampton 1976 e Lawson 1982). A figura 3 sintetiza estas relações, ressaltando, ainda, a importância do grau de confinamento no desenvolvimento dos dois tratos de fácies.

Hidrodinâmica confinada $\mathrm{O}$ trato confinado iniciase com os fluxos de detritos canalizados que, em razão da alta viscosidade, são fluxos coesivos de material extremamente heterogêneo. Os seixos e matacões flutuam em matriz argilosa ou arenosa que os sustenta durante o transporte. Inicialmente, os fluxos de detritos são completamente desorganizados em sua estrutura interna, mas, gradativamente, vão adquirindo um caráter laminar com o decréscimo da viscosidade ao longo do transporte. Walker (1978) postula que o grau de organização de sedimentos rudáceos se faz de modo transicional, refletindo a distância percorrida pelo fluxo antes de sua deposição. No Subgrupo Itararé, esta transição é carac- 


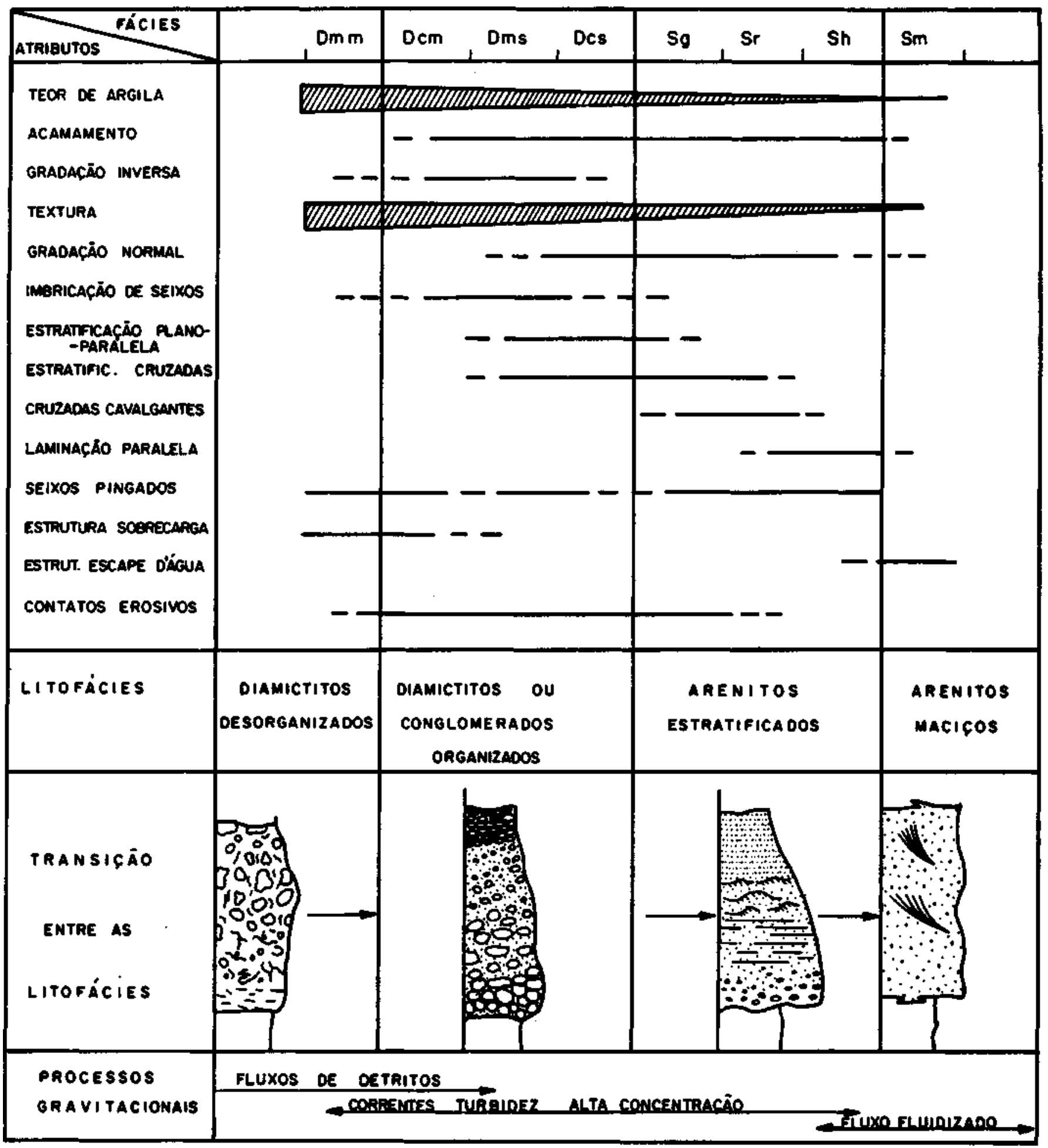

Figura 2- Trato não-confmado de fácies de ressedimentação do Subgrupo Itararé na região de Porto Feliz (SP) Figure 2 - Resedimentation unconfined facies tract of the Itararé Subgroup in the Porto Feliz city region (São Paulo State)

terizada pelo desenvolvimento de incipiente imbricação de seixos, seguida de gradação inverso-normal e finalmente de estratificação por ação de processos tracionais em condições distais. A deposição final poderá ocorrer em qualquer estágio desta transição, assim que a massa em movimento atingir uma posição de equilíbrio com a declividade da superfície deposicional. Como decorrência, os diamictitos resultantes poderão exibir desde uma completa desorganização, à semelhança dos verdadeiros tilitos, até se apresentarem como diamictitos acamados, gradados e/ou com seixos imbricados. Os primeiros compõem a litofácies diamictitos desorganizados e os últimos, a litofácies diamictitos organizados.

Na seqüência do processo, o descréscimo da viscosidade e/ ou concentração, torna o fluxo menos coesivo, aumentando a sua velocidade, resultando na mudança de fluxo laminar para turbulento, de onde derivam as correntes de turbidez de alta concentração. Esta passagem é destacadamente transicional em condições confinadas, onde seixos e calhaus são sustentados em suspensão por turbulência, flutuação e pressão dispersiva (Lowe 1982). A deposição ocorre quando a velocidade de fluxo 


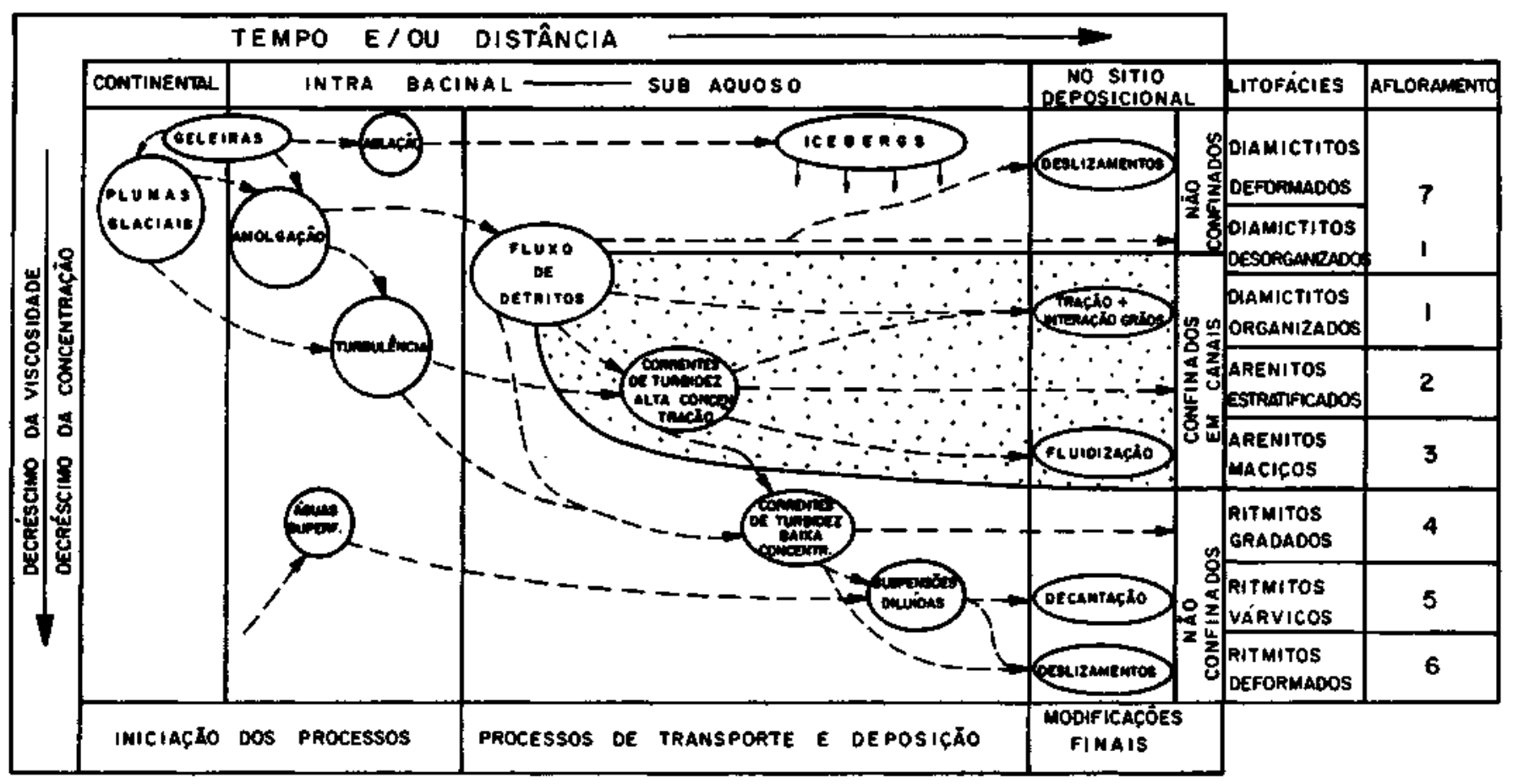

Figura 3 - Modelo hidrodinâmico da ressedimentação do Subgrupo Itararé na região de Porto Feliz (SP)

Figure 3 - Itararé Subgroup hydrodynamic resedimentation model in the Porto Feliz city region (São Paulo State)

decresce a um valor no qual a dispersão dos clastos não pode ser mantida. Os clastos maiores decantam rapidamente, sendo submetidos a variadas modificações finais, dentre as quais, o choque entre grãos, por ação da pressão dispersiva, e fluidização/liquefação, por escape de fluidos. Estes processos podem imprimir características faciológicas marcantes no turbidito resultante. Outro mecanismo tardio, mas igualmente importante na caracterização faciológica, decorre do desenvolvimento de um tapete de grãos sobre o qual atuam processos tracionais derivados de correntes turbulentas remanescentes. As fácies resultantes até este estágio são conglomerados arenosos a arenitos seixosos, podendo exibir gradação inversa ou normal, estratificação bem desenvolvida ou caráter maciço, dependendo dos processos finais durante a deposição. Estas fácies são extremamente semelhantes às fácies fluviais de ambiente continental.

Uma vez depositados os clastos mais grossos, as correntes de turbidez de alta concentração passam a transportar uma população de grãos mais bem selecionados, predominantemente da classe arenosa. Embora a viscosidade tenha diminuído, admite-se que os fluxos sejam de menor velocidade, devido ao decréscimo da concentração e, supostamente, ao menor declive da superfície deposicional encontrada em situações mais distais. Os depósitos formados nestas condições são turbiditos arenosos, com a seqüência clássica de Bouma (1962). Na região de Porto Feliz, o Subgrupo Itararé apresenta inúmeras variações nesta seqüência, sendo que as mais freqüentes exibem seqüências Tabc, Tbc e Tbcd. Pickering et al. (1986) atribuem estas variações a diferenças na velocidade do fluxo, razão de desaceleração, distribuição granulométrica e grau de homogeneidade desta distribuição no interior do fluxo, particularmente entre o corpo e a cauda das correntes de turbidez. Estes parâmetros condicionam a relativa importância da decantação e tração e, também, os regimes de fluxo superior e inferior, que determinarão as divisões de Bouma (1962). Esses turbiditos arenosos, juntamente com os conglomerados arenosos e arenitos seixosos discutidos anteriormente, constituem a litofácies arenitos estratificados.

$\mathrm{O}$ trato confinado de fácies do Subgrupo Itararé encerra-se com os arenitos maciços ou arenitos onde as estruturas primá- rias encontram-se parcial ou totalmente obliteradas. Tais características são aqui atribuídas à fluidização por escape d'água nos momentos finais da deposição. Esta fluidização ocorre quando a deposição é extremamente rápida, aprisionando grande quantidade de água nos vazios intersticiais. $\mathrm{O}$ fator que controla a rapidez de decantação, e portanto a fluidização, é o grau de confinamento do fluxo turbulento. $\mathrm{O}$ escape da água provoca a fluidização com o subseqüente fluxo de acomodação. Este fluxo, apesar de atingir distâncias mínimas, na escala de alguns metros, é suficiente para mascarar as estruturas originais. A íntima associação da fácies arenito maciço com os turbiditos arenosos e com fácies pelíticas evidencia que a rápida desaceleração do fluxo pode ter ocorrido na passagem de condições confinadas para não-confinadas, na porção terminal dos canais subaquosos. O fluxo, perdendo confinamento, desacelera-se rapidamente, depositando imediatamente sua carga sedimentar. Estes depósitos compõem, isoladamente, a litofácies arenito maciço.

Os processos descritos, como já afirmado, constituem um contínuo e transicional espectro de fluxos atuantes em condições confinadas. Como decorrência, as fácies resultantes compõem um trato de fácies transicionais que variam continuamente desde diamictitos desorganizados até arenitos maciços, passando por vários graus de organizações dos diamictitos, conglomerados e arenitos conglomeráticos, igualmente com várias características transicionais, e arenitos gradados com diferentes seqüências de Bouma (1962). As quatro litofácies modeladas representam este trato transicional como elementos discretos de um espectro contínuo de fácies presentes no Subgrupo Itararé na região de Porto Feliz.

Hidrodinâmica não-confinada $\mathrm{O}$ segundo trato de fácies de ressedimentação na área em estudo deriva de processos gravitacionais atuantes em condições abertas e não confinadas. Este trato inicia-se, igualmente, com aja analisada litofácies diamictitos desorganizados, depositada por fluxos de detritos. Em condições não confinadas, este fluxo gravitacional coesivo gera, mesmo em áreas proximais, correntes de turbidez de baixa concentração. Estas podem ainda ser 
derivadas da diluição das correntes de alta concentração em condições distais ou a partir de transbordamentos das mesmas correntes confinadas nos canais subaquosos. As correntes de turbidez de baixa concentração são fluxos gravitacionais turbulentos de baixa velocidade e, portanto, caracterizadas pelo transporte das frações arenosas mais finas e, predominantemente, siltes e argilas. A deposição se faz pela interação entre tração, seguida de decantação, o que assinala, de maneira marcante, a natureza episódica dos eventos gravitacionais. Como decorrência, os turbiditos formados se apresentam como ritmitos com variações na seqüência vertical de estruturas, das quais as mais abundantes na região de Porto Feliz são Tcd(e), Tbcd(e) e Ta(e). Esta última parece indicar correntes de turbidez de baixa concentração produzidas por transbordamentos, quando toda a carga arenosa é depositada repentinamente por decantação, sem desenvolvimento de processos tracionais. A litofácies ritmitos gradados representa este estágio do trato não-confinado.

Associados, no tempo, por intercalação, e no espaço, por variações laterais, ocorrem ainda na área estudada, particularmente na região de Itu, os ritmitos com laminação várvica. O processo sedimentar inferido para esta fácies é a simples decantação das nuvens caudais das correntes de turbidez de baixa concentração mais intensamente diluídas. Duas hipóteses são aqui levantadas para explicar o caráter várvico desta fácies: a. interferência sazonal de suspensões derivadas de correntes superficiais, cujas características texturais seriam diferentes das nuvens caudais diluídas; a periodicidade dos eventos turbulentos produziria a segregação das lâminas claras e escuras; b. presença de correntes de profundidade responsáveis pelas lâminas claras seguidas de decantação das nuvens caudais escuras. É interessante ressaltar que, com muita freqüência, na região estudada, os ritmitos várvicos constituem o horizonte $d$ de Bouma (1962) dos ritmitos gradados, demonstrando, assim, suas íntimas relações genéticas.

Um dos aspectos notáveis das fácies do trato não-confinado é a abundância de convoluções e deformações. Ocorrem tanto em diamictitos desorganizados, quanto em ritmitos gradados ou várvicos, sendo raras em diamictitos organizados e ausentes em fácies arenosas. Estas deformações são atribuídas a deslizamentos em condições não-confinadas de depósitos ainda não completamente consolidados. Nos depósitos com deslizamentos foi possível reconhecer as feições sindeposicionais. Estes deslizamentos representam, em última análise, uma ressedimentação local de fácies de ressedimentação, posto que processos gravitacionais são reconhecidos em ambas as fases.
Os deslizamentos são de dois tipos na região estudada: a. deslizamentos caóticos, envolvem total ou parcialmente diferentes camadas e estão preferencialmente associados aos diamictitos desorganizados; estas características lhes conferem um caráter sin-deposicional; b. deslizamentos subordinados a superfícies estratais, restritos aos ritmitos; estes deslizamentos são atribuídos a incrementos da declividade da superfície deposicional com a superposição dos depósitos de sucessivos eventos gravitacionais. Em condições proximais aos focos de suprimento, o volume de sedimentos depositados é maior do que em condições distais. Assim, após cada evento gravitacional, a co-extensão de cada lobo turbidítico provocaria sucessivos acréscimos de declividade na superfície deposicional até que a componente gravitacional, atuando sobre uma pilha relativamente espessa de sedimentos não consolidados, supere a resistência de atrito de uma das superfícies estratais, provocando o deslizamento. Os ritmitos produzidos por correntes geradas por transbordamentos de canais subaquosos oferecem as condições ideais para o desenvolvimento do mecanismo acima descrito. Embora plausível, não foi possível constatar a relação de tais deslizamentos com a geração de novos eventos gravitacionais.

CONSIDERAÇÕES FINAIS A presença de fácies de ressedimentação no Subgrupo Itararé tem sido constatada pela grande maioria dos autores estudiosos desta unidade estratigráfica da Bacia do Paraná. Entretanto, este aspecto não tem merecido o devido destaque. É opinião dos presentes autores que as fácies de ressedimentação representam, ao lado das fácies periglaciais costeiras e marinhas, a maior parte dos sedimentos Itararé, enquanto que as fácies depositadas diretamente pelos glaciares não detêm a importância volumétrica que lhes tem sido atribuída. Neste sentido, entende-se que o fator preponderante no controle da sedimentação Itararé relaciona-se com os ciclos de variação relativa do nível do mar. Estes ciclos, ao elevarem o nível de base regional, controlaram não só o espaço de acomodação de sedimentos como também o volume e natureza do suprimento terrígeno. Exerceram, portanto, um efetivo domínio sobre a expansão da bacia deposicional nos sucessivos episódios de sedimentação glacial e sobre a arquitetura deposicional das seqüências resultantes. Controlaram, igualmente, a organização faciológica destas seqüências através de um específico arranjo de fácies costeiras progradacionais, fácies de ressedimentação retrogradacionais e marinhas agradacionais.

Com este enfoque, as fácies analisadas do Subgrupo Itararé são entendidas, na região estudada, como produto de ressedimentação a partir dos depósitos glaciogênicos, com os glaciares desempenhando função mais efetiva de agentes de suprimento.

\section{REFERÊNCIAS BIBLIOGRÁFICAS}

BARBOSA, O. \& ALMEIDA, F.F.M. 1949. Nota sobre a estratigrafia da Série Tubarão, no Estado de São Paulo. An. Acad. bras. Ciên., 21(1):65-68. BOULTON G.S. 1981. A reply to Dr. Blake's comments. Boreas, 10:129-131.

BOUMA, A.M. 1962. Seclimentology of Some Flysch Deposits. Amsterdam, Elsevier. $168 \mathrm{p}$

CAETANO-CHANG, M.R. 1984. Análise Ambiental e Estratigráfica do Subgrupo Itararé $(P C)$ no Sudoeste do Estado de São Paulo. São Paulo. $232 \mathrm{p}$. (Tese de Doutoramento, IG/USP).

CAETANO-CHANG, M.R. \& LANDIM, P.M.B. 1983. Interpretação ambiental da seção Itaporanga-Taquarituba, SW do Estado de São Paulo (Sub-grupo Itararé). In: SIMP. REG. GEOL., 4. São Paulo. Bol. Resumos... São Paulo, SBG/NSP. p. 16.

COLEM AN, A.P. 1918. Permo-Carboniferous glacial deposits of South America. J. Geol, 26(4):310-324.

DERBY, O.A. 1878. Geologia da região diamantífera da Província do Paraná no Brasil. Arch. Mus. Nac., 3:89-96

EYLES, N.; EYLES, C.H.; MIALL, A.D. 1983. Lithofacies types and vertical profile models; an alternative approach to the description and environmen interpretation of glacial diamict and diamictite sequences. Sedimentology, 30:393-410.

FRAKES, L.A. \& CROWELL, J.C. 1969. Late Paleozoic glaciation: I South America. Geol. Soc. Am. Bull. 80(6): 1007-1042.

FULFARO, V.J. \& LANDIM, P.M.B. 1976. Stratigraphic sequences of the intracratonic Paraná Basin. Newsletter Stratigraphy, 4:150-168.
FULFARO, V.J.; STEVAUX, J.C.; SOUZA E.E., P; BARCELOS, J.H. 1984. A Formação Tatui (P) no Estado de São Paulo. In: CONGR BRAS. GEOL., 33. Rio de Janeiro. Anais.. Rio de Janeiro, SBG. v. 2, p. $711-724$

GAMA, E.G., Jr.; BANDEIRA, A.N., Jr.; FRANÇA, A.B. 1982. Distribuição espacial e temporal das unidades litoestratigráficas paleozóicas na parte central da Bacia do Paraná. Rev. Bras. Geoc. 12(4):578-589.

GAMA E.G., Jr; CAETANO, M.R · WEYLER, G. 1980. Divisão faciológica do Subgrupo Itararé no centro-oeste do Estado de São Paulo. In: CONGR. BRAS. GEOL., 31. Camboriú. Resumos... Camboriú, SBG. p. 365.

GAMA, E.G., Jr.; PERINOTTO, I.A.I.; RIBEIRO, H.I.P.S.; PADULA, E.K 1992. Contribuição ao estudo da ressedimentação no Subgrupo Itararé: um Guia Temático de Campo. Rev. Bras. Geoc. 22(2):237-247.

GRAVENOR, C.R. \& ROCHA-CAMPOS, A.C. 1983. Patterns of Late Paleozoic glacial sedimentation on the southeast side of the Paraná Basin, Brazil. Paleogeogr. Paleoclimatol. Paleoecol., 43:1-39.

LANDIM, P.M.B. \& BARROS, M.B.R. 1972. Distincão de tilitos dentre os mistitos do Subgrupo Itararé. Rev. Bras. Geoc., 2(4):270-274.

LANDIM, P.M.B. \& SOARES, P.C. 1979. Mapeamento Faciológico do Grupo Tubarão. São Paulo, Convênio DAEE-UNESP. (Rei. Final).

LAWSON, D.E. 1982. Mobilization, movement and deposition of active subaerial sediment flows, Matanuska Glacier, Alaska. J. Geol 90:279-300.

LEINZ, V. 1937. Estudos sobre a Glaciação Permo-Carbonifera do Sul do Brasil. DNPM/DFPM. 47 p. (Boletim 21). 
LOWE, D.R. 1979. Sediment gravity flows; their classification and some problems of application to natural flows. In: DOYLE, L.J. \& PILKEY, O.H., Jr. eds. Geology of Continental Slopes. USA, Soc. Econ. Paleontol. Min. p. 75-82 (Spec. Pub. 27).

LOWE, D.R. 1982. Sedimentary gravity flows: $n$ Depositional models with special reference to the deposits of high-density turbidity currents. J. Sed. Petrol, 52(1):279-297.

MIALL, A.D. 1983. Glaciomarine sedimentation. Gowganda Formation (Huronian) northern Ontario. J. Sed. Petrol, 53:477-491.

MIALL, A.D. 1985. Principles of Sedimentary Basin Analysis. 2 ed. New York, Springer-Verlag. 490 p.

MIDDLETON, G.V. \& HAMPTON, M.A. 1976. Subaqueous sediment transport and depositon by sediment gravity flows. In: STANLEY, D.J. \& SWIFT, D.J.P. eds. Marine Sediment Transport and Environmental Management. New York, Wiley \& Sons, p. 197-218.

NORTHFLEET, A.A.; MEDEIROS, R.A.; MUHLMANN, H. 1969. Reavaliação dos dados geológicos da Bacia do Paraná. Bol. Tec. Petrobrás. 12(3):291-346.

PERINOTTO, J.A.J. 1987. finalise Estratigráfica da Seqüência Portadora de Carvão na Região de Cerquilho (SP). São Paulo. 76 p. (Dissertação de Mestrado, IG/USP).

PETRI, S. 1964. Campo Tubarão. In: Inst, Geogr. Geol. ed. Geologia do Estado de São Paulo. São Paulo, IGG. p. 56-63. (Boletim 41).

PICmUNG, K.; STOW, D.; WATSON, M.; HISCOTT, R. 1986. Deep water facies, processes and models. A review and classification scheme for modem and ancient sediments. Earth Sci. Rev., 23:75-174.

ROCHA-CAMPOS, A.C. 1967. The Tubarão Group in the Brazilian portion of the Paraná Basin. In: BIGARELLA, J.J.; BECKER, R.R. PINTO, I.D. eds. Problems in Brazilian Gondwana Geology. Curitiba, IG/UFPR. p. $27-102$.

ROCHA-CAMPOS, A.C. \& SUNDARAM, P. 1981. Geological and palinological observations on Late Paleozoic varvites from Itararé Subgroup Paraná Basin. In: CONOR. LATINO-AM. PALEONT., 2. Porto Alegre, 1981. Anais... Porto Alegre, v. 1, p. 257-275.
SAAD, A.R. 1977. Estratigrafia do Subgrupo Itararé no Centro e Sul do Estado de São Paulo. São Paulo. 107 p. (Dissertação de Mestrado, $\mathrm{IG} / \mathrm{USP})$.

SANTOS, P.R. 1979. Distribuição Estratigráfica, Características e Facies de Diamictitos e Rochas Associadas do Subgrupo Itarare no Centro Sul do Estado de São Paulo. São Paulo. (Dissertação de Mestrado, IG/USP).

SANTOS, P.R. 1987. Facies e Evolução Paleogeográfica do Subgrupo Itararé/Grupo Aquiduana (Neopaleozócio) na Bacia do Paraná, Brasil. São Paulo. v. 1, 128 p. (Tese de Doutoramento, IG/USP).

SOARES, P.C.; LANDIM, P.M.B.; SINELLI, O.; WERNICK, E.; WU, F.T.; FIORI, A.P. 1977. Associações litofaciológicas do Subgrupo Itararé e sua interpretação ambiental. Rev. Bras. Geoc., 7(2):131-149.

SOUZA, E.E., F. 1986. Mapeamento Faciológico do Subgrupo Itararé na Quadrtcula de Campinas (SP). São Paulo. 121 p. (Dissertação de Mestrado, IG/USP).

STEVAUX, J.C.; SOUZA E.E., Fo; FULFARO, V.J. 1986. Trato deposicional da Formaç̃o Tatuí (P) na área aflorante do NE da Bacia do Paraná, Estado de São Paulo. In: CONGR. BRAS. GEOL., 34. Goiânia. Anais... Goiânia, SBG. v. 1, p. 219-229.

WALKER, R.G. 1978. Deep water sandstone facies and ancient submarine fans: Models for exploration of stratigraphic traps. Am. Assoc. Petrol Geol. Bull, 62(6):932-966.

WALKER, R.G. 1984. Facies Models. 2 ed. Toronto, Geol. Assoc. Canada. 211 p. (Geoc. Can. Reprint. Serie 1).

WASHBURNE, C.W. 1930. Petroleum geology of the State of São Paulo. Bol Com. Geogr. Geol, $\mathrm{n}^{\circ} 22$.

WOODWORTH, J.B. 1912. Geological expedition to Brazil and Chile, 19081909. Bull. Mus. Comp. Zool, 56(1):1-137. (Geol. Series 10).

MANUSCRITO A698

Recebido em 8 de abril de 1991

Revisão do autor em 22 de maio de 1992 Revisão aceita em 29 de maio de 1992 